\title{
Optimal Integration of Distributed Generation in Distribution System: A Case Study of Sallaghari Feeder from Thimi Switching Station, Bhaktapur, Nepal
}

\author{
Basanta Pancha ${ }^{1,2}$, Rajendra Shrestha ${ }^{1,3}$, Ajay Kumar Jha ${ }^{1,4}$ \\ ${ }^{1}$ Department of Mechanical Engineering, Pulchowk Campus, IOE, TU, Lalitpur, Nepal \\ Corresponding author: ${ }^{2}$ basanta.pancha@gmail.com, ${ }^{3}$ rsfluid@hotmail.com, ${ }^{4}$ akjha@ioe.edu.np
}

Received: Nov 2, 2018

Revised: Jan 3, 2019

Accepted: Jan 5, 2019

\begin{abstract}
The modern power distribution network is constantly being faced with an ever-growing load demand resulting into increased burden and reduced voltage, which leads to find alternative source of energy to meet it. In Nepal, the electricity supply is based on hydropower primarily, which are situated very far from load centers and hence the generated power are to be transmitted through transmission and distributed system. Among the systems, radial distribution system is popular because of low cost and simple design, but it has power quality issues like low voltage profile and higher loss. In response to the problem of increased load demand, efforts have been made to decentralize this infrastructure through the use of distributed generators. However, the improper sizing and placement of DG unit may lead to higher power loss and power instability. The optimization problem of DG unit placement and its capacity determination were performed in this research. The study has been carried out for Thimi-Sallaghari Feeder and this feeder has low voltage profile and higher power loss. The IEEE 33 bus test system was examined as a test case to demonstrate the effectiveness of the proposed approach. The study has been carried out in MATLAB using "Backward and Forward Sweep Method" for load flow analysis and Genetic Algorithm for optimization. The number of DG unit of different size integrated was varied from one to ten. The result of this study showed that the voltage at minimum voltage node, maximum active and reactive loss reduction of Thimi-Sallaghari feeder have been improved by $3.69 \%$ (from 0.942 p.u. to 0.976 p.u), $75.88 \%$ and $75.88 \%$ respectively with placement of DG units at three bus locations of total $658.2019 \mathrm{~kW}$ and 395.873 kVAR capacity. Likewise, the voltage at minimum voltage node, maximum active and reactive loss of IEEE- 33 bus system have been improved by $6.88 \%, 90.11 \%$ and $89.9 \%$ respectively with placement of DG units of total $2215.488 \mathrm{~kW}$ and 1176.059 kVAR at 6 different locations of the network.
\end{abstract}

Keywords: Distributed generation, optimal DG allocation, genetic algorithm 


\section{Introduction}

Load demand is increasing day by day and it is economically, technically and environmentally not recommended to meet the increasing load demand through constructing new hydropower and expanding transmission and distribution system. Therefore, small distributed generating plants fueled by renewable energy sources can be integrated at the load centers to meet the load demand. The losses in the distribution system are significantly high as compared to that in transmission system due to low distribution voltage levels. Strategies like network reconfiguration, shunt compensator, optimal selection of conductors and above all DG penetration can be done to reduce the power losses and to improve the voltage profile of the system. Distribution Generation can be defined as "an electric power generation source connected directly to the distribution network or on the customer side of the meter [1]. The integration of DG units facilitates the voltage profile improvement and power loss reduction along with restructure planning for the utility thereby increasing reliability of the distributed system [3].

Optimal DG unit size and planning for DG unit location were used to improve the voltage profile and efficiency of the system. M. Gomez-Gonzalez introduced a hybrid approach which employed discrete particle swarm optimization (PSO) and optimal power flow [4]. Genetic Algorithm (GA) mimics the process of evolution and the most promising individuals have greater chances of transmitting their genes to offspring [5]. The DG unit placement in distribution system impacts the power flow and voltage conditions at consumers of the utility equipment [6].

\section{Methodology}

The proposed methodology for optimization of DG size and its placement formulation has an objective function of minimizing active and reactive power loss using Genetic Algorithm under given constraints. The codes used in MATLAB scripting language were initially verified for IEEE standard 33 bus system and then were applied for $11 \mathrm{kV}$ Thimi-Sallaghari Feeder of Bhaktapur distribution system network consisting 11 buses. The load flow analysis was done using sweep algorithm to find power losses and bus voltages of the system. Minimum tolerance of objective function value was considered as the convergence criteria. The optimization was done for one to ten DG unit placements and financial analysis was also performed for each cases.

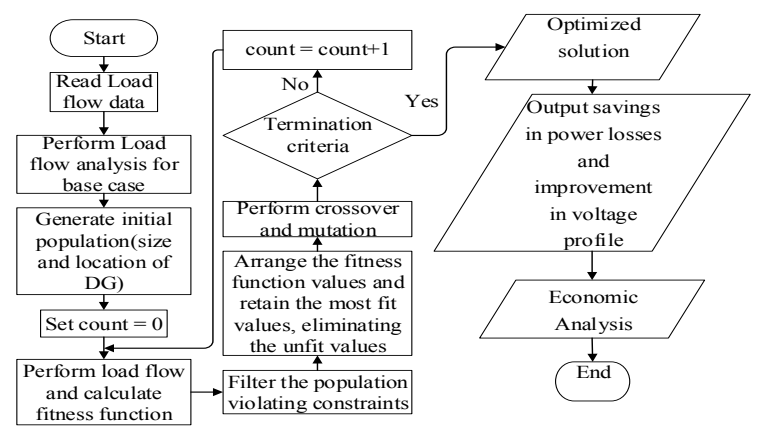

Fig. 1: Flowchart of load flow and optimization using GA algorithm 


\subsection{Data Collection}

The secondary data includes line data (resistance and reactance) and load data (active load and reactive load) of Sallaghari Feeder [7].

\subsection{Load flow analysis using Sweep algorithm}

Branch current was calculated from end node to source node in backward sweep and in forward sweep, the node voltage was calculated from source node to end node.

\subsection{Objective Function Formulation}

This study has performed assessment with objective function in order to find the optimum placement and sizing of DG under subjected constraints into an IEEE 33 buses test network and Sallaghari Feeder.

\subsubsection{Minimization of Active and Reactive Power Loss:}

If $\mathrm{P}_{\mathrm{L}}$ and $\mathrm{Q}_{\mathrm{L}}$ denotes active and reactive power loss which should be minimum and determined by equation (1) and (2) respectively:

$$
\begin{aligned}
\operatorname{Min~}_{1}=\mathrm{P}_{\mathrm{L}} & =\sum_{i=1}^{m} I_{i}{ }^{2} R_{i} \\
{\text { Min } \mathrm{f}_{2}}=\mathrm{Q}_{\mathrm{L}} & =\sum_{i=1}^{m} I_{i}{ }^{2} X_{i}
\end{aligned}
$$

Where I, R, X, $\mathrm{m}$ are branch current, resistance, reactance and branch number respectively.

\subsubsection{Minimization of Size of DG:}

If $\mathrm{Q}_{\mathrm{C}}$ and $\mathrm{Pg}$ are total reactive and active power of DG respectively which should be minimized and is represented by equation (3):

$$
\begin{aligned}
& \text { Min } \mathrm{f}_{3}=\mathrm{Q}_{\mathrm{C}}+\mathrm{Pg}=\sum_{i=1}^{n} Q_{C_{i}}+\mathrm{Pg}_{\mathrm{i}} \\
& \text { where } \mathrm{n} \text { is number of node. } \\
& 0.85 \leq \text { power factor } \leq 1 \text {; } \\
& 0 \leq \mathrm{Pg} \leq 60 \% \text { of } \mathrm{P}_{\text {total }} \text {; where, } \mathrm{P}_{\text {total }} \text { is the total active power of the bus loads. }
\end{aligned}
$$

\subsubsection{Operation Constraints:}

The voltage magnitude at each bus (V) after the placement of DG must be within a permissible range and is expressed as:

0.95 p.u. $\leq \mathrm{V} \leq 1.05$ p.u.

\section{Results and Discussion}

\subsection{Optimal Allocation of DG unit in IEEE 33 Bus Test System}

The single line diagram of test system IEEE 33 bus system is shown in Fig. 2 [2]. 


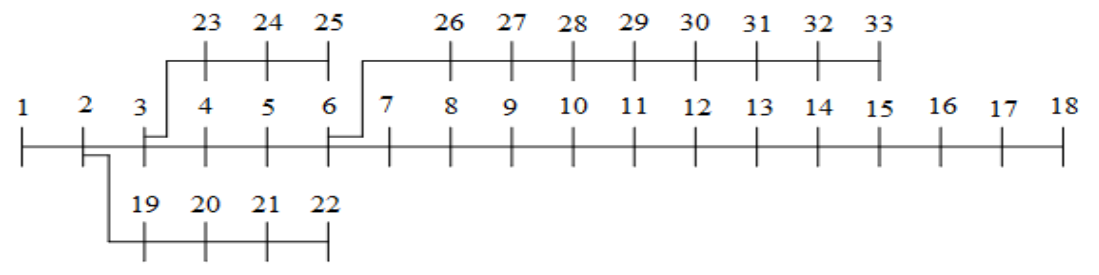

Fig. 2: IEEE 33 bus system

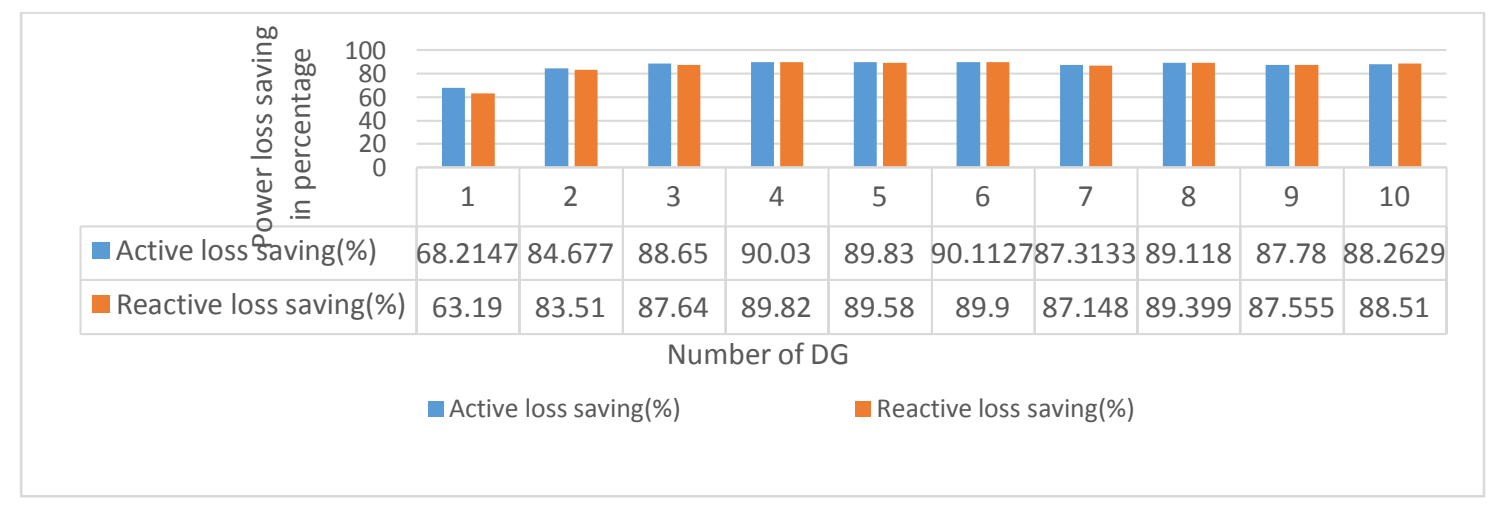

Fig. 3: Power loss saving profile of IEEE 33 bus system for up to 10 DG units

The results of optimization as shown in Fig. 3 have shown that the maximum active and reactive loss saving was minimized to $19.9616 \mathrm{~kW}(90.117 \%$ saving) and $13.5954 \mathrm{kVAR}(89.9025 \%$ saving) respectively from six DG integration at bus 8 (301.525 kW and $158.482 \mathrm{kVAR})$, bus 13 (461.237 kW and 253.393 kVAR), bus 14 (89.169 kW and $41.941 \mathrm{kVAR})$, bus 25 (415.896 kW and $166.741 \mathrm{kVAR})$, bus 30 (787.493 kW and $476.767 \mathrm{kVAR})$ and bus 33 (160.168 kW and $78.734 \mathrm{kVAR}$ ) of total size $2215.48 \mathrm{~kW}$ and $1176.059 \mathrm{kVAR}$. Similarly, the minimum p.u bus voltage was improved to 0.9809 p.u ( $7.39 \%$ improvement).

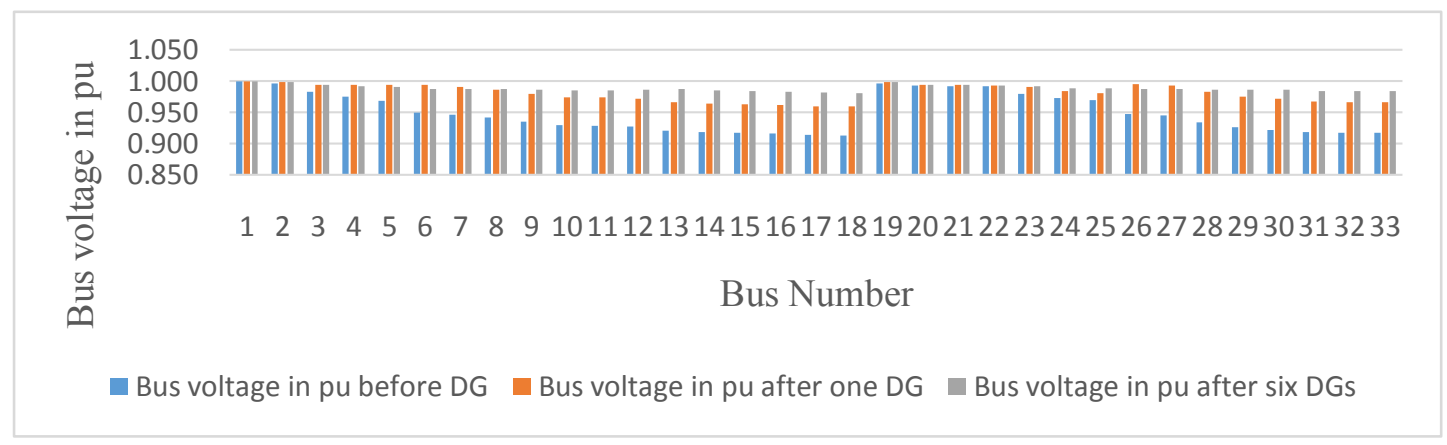

Fig. 4: Voltage profile of IEEE 33 bus system

The optimization results for single DG placement have shown that the total active and reactive power loss has been reduced to $64.172 \mathrm{~kW}(68.2147 \%$ saving) and $49.5613 \mathrm{kVAR}(63.19 \%$ saving) respectively with the integration of a DG of size $2228.99 \mathrm{~kW}$ and $1381.41 \mathrm{kVAR}$ at bus 26. Similarly, the minimum bus p.u voltage was improved to 0.9593 p.u from 0.9133 p.u (5.03\% improvement). 


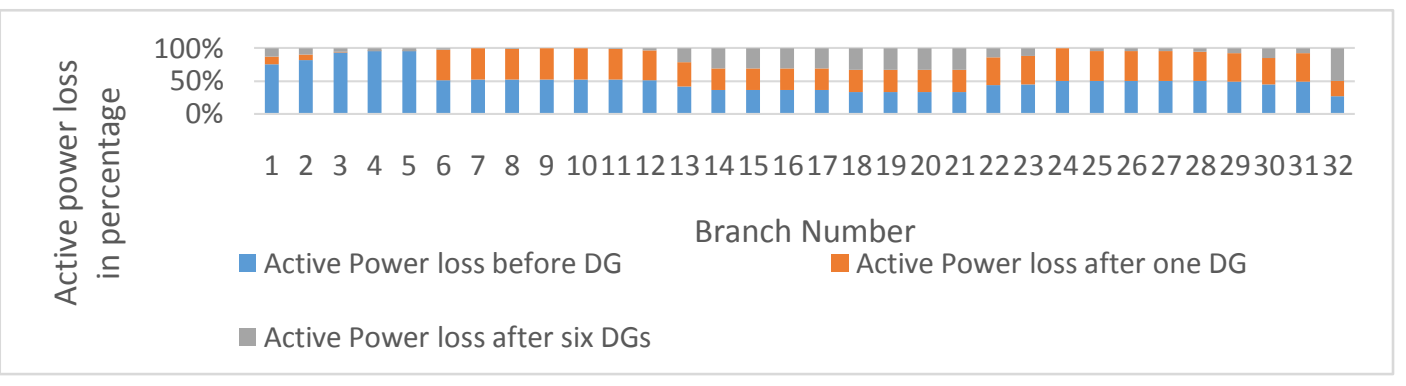

Fig. 5: Active Power loss profile of IEEE 33 bus system

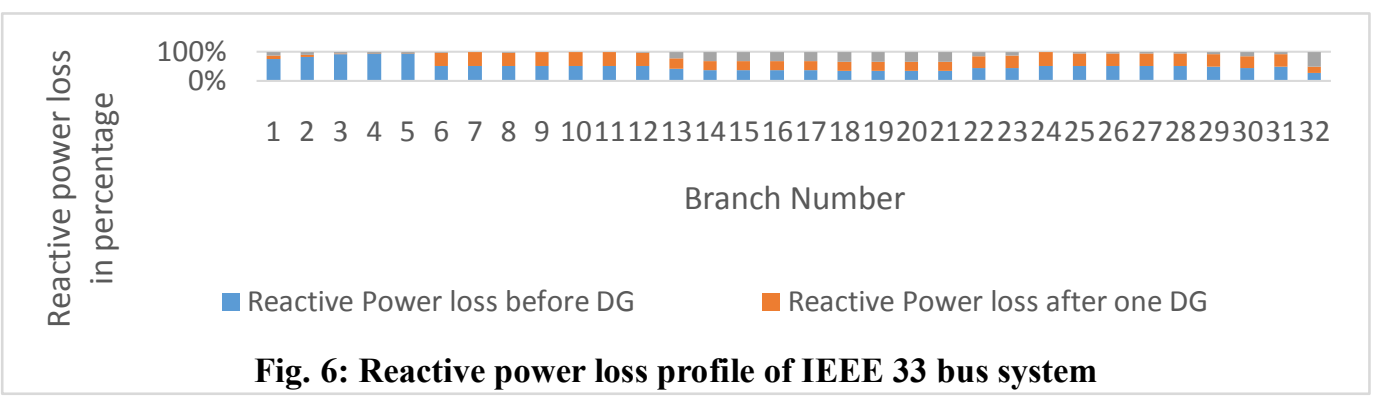

\subsection{Optimal Allocation of DG unit in Thimi-Sallaghari Feeder}

The distribution feeder of Thimi-Sallaghari network and load and line data are shown in Fig. 7 and Table 1 respectively [7].

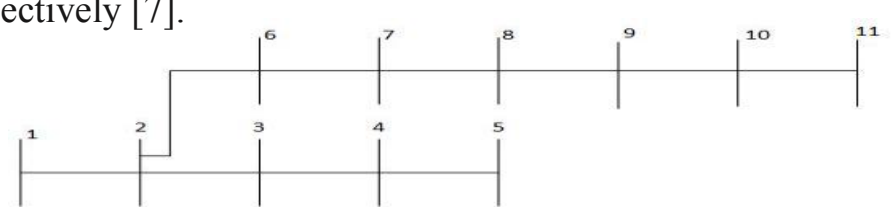

Fig. 7: Thimi-Sallaghari 11 bus distribution feeder

Table 1: Load and line data of Thimi-Sallaghari 11 Bus feeder

\begin{tabular}{|c|l|c|c|c|c|c|c|c|}
\hline $\begin{array}{c}\text { Bus } \\
\text { Num. }\end{array}$ & \multicolumn{1}{|c|}{$\begin{array}{c}\text { Bus } \\
\text { Name }\end{array}$} & $\begin{array}{c}\text { Active } \\
\text { Power } \\
(\mathrm{kW})\end{array}$ & $\begin{array}{c}\text { Reactive } \\
\text { Power } \\
\text { (kVAR) }\end{array}$ & From & To & $\begin{array}{c}\text { Branch } \\
\text { Number }\end{array}$ & $\begin{array}{c}\mathrm{R} \\
\text { (ohm) }\end{array}$ & $\begin{array}{c}\mathrm{X} \\
(\mathrm{ohm})\end{array}$ \\
\hline 1 & Substation & 0 & 0 & 1 & 2 & 1 & 1.695 & 1.575 \\
\hline 2 & NEA & 80 & 60 & 2 & 3 & 2 & 0.968 & 0.8995 \\
\hline 3 & Plastic Factory & 96 & 128 & 3 & 4 & 3 & 0.9705 & 0.9018 \\
\hline 4 & Near Plastic Factory & 128 & 96 & 4 & 5 & 4 & 1.017 & 0.945 \\
\hline 5 & Yeti Carpet & 120 & 160 & 2 & 6 & 5 & 0.678 & 0.63 \\
\hline 6 & Siya Ram Textile & 90 & 120 & 6 & 7 & 6 & 1.017 & 0.945 \\
\hline 7 & Annapurna Paper & 189 & 252 & 7 & 8 & 7 & 0.5755 & 0.5348 \\
\hline 8 & Duwakot 2 & 80 & 60 & 8 & 9 & 8 & 0.5713 & 0.5309 \\
\hline 9 & KNK Hostel & 80 & 60 & 9 & 10 & 9 & 0.6056 & 0.5627 \\
\hline 10 & KMC & 160 & 120 & 10 & 11 & 10 & 0.6441 & 0.5985 \\
\hline 11 & Duwakot Phasintar & 80 & 60 & & & & & \\
\hline
\end{tabular}




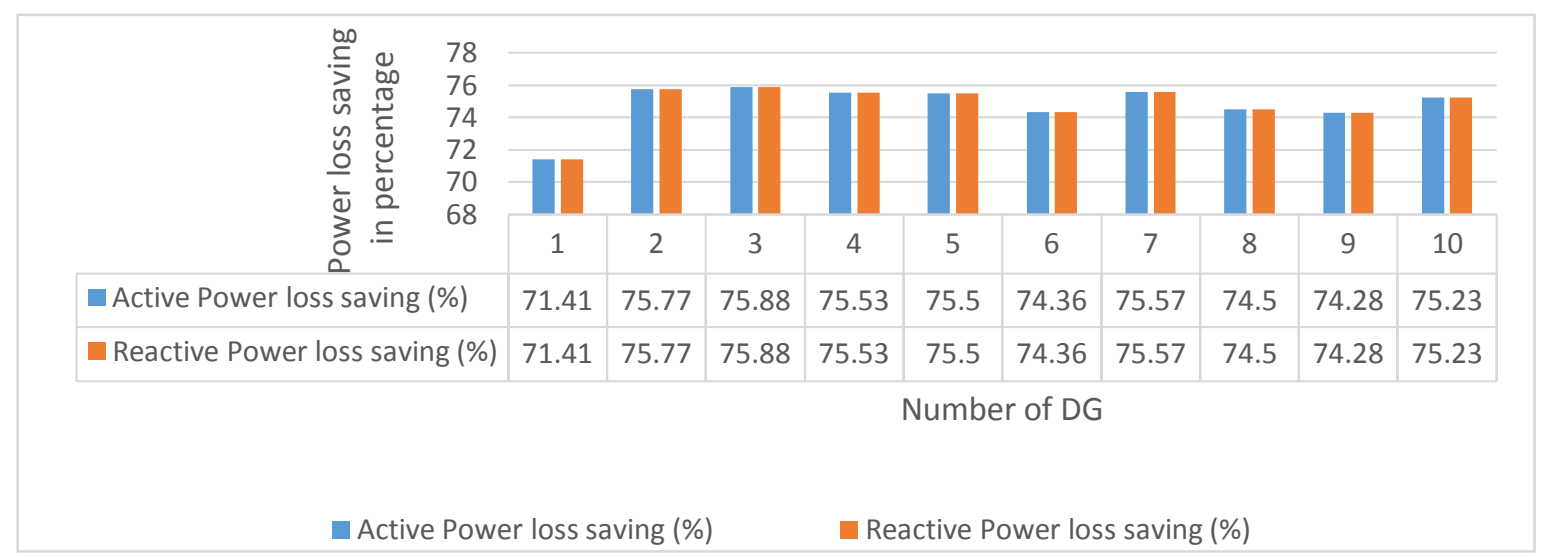

Fig. 8: Power loss saving profile of 11 bus Sallaghari Feeder bus system for up to 10 DG unit

The optimization results as shown in Fig. 8 have shown that the maximum active and reactive loss was minimized to $13.567 \mathrm{~kW}(75.88 \%$ saving) and $12.6065 \mathrm{kVAR}$ (75.889\% saving) respectively from three DG integration at bus 5 (195.036 kW and $116.963 \mathrm{kVAR})$, bus 8 (175.620kW and 102.793kVAR) and bus 10 (287.545 kW and $176.117 \mathrm{kVAR})$ of total size $658.2019 \mathrm{~kW}$ and $395.87 \mathrm{KVAR}$. Similarly, the minimum p.u bus voltage was improved to 0.9768 p.u (3.694\% improvement).

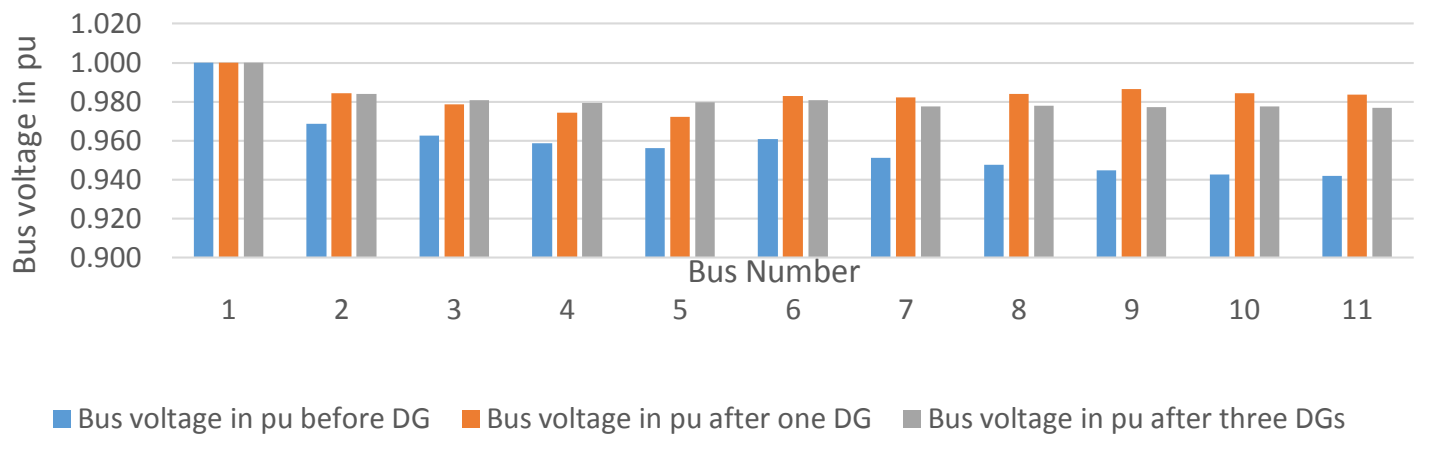

Fig. 9: Voltage profile of Sallaghari 11 bus system

The optimization results for single DG placement have shown that the total active and reactive power loss was reduced to $16.0841 \mathrm{~kW}$ (71.4152\% saving) and $14.9456 \mathrm{kVAR}(71.4149 \%$ saving) respectively with the integration of a DG of size $661.7926 \mathrm{~kW}$ and $410.1405 \mathrm{kVAR}$ at bus 9. Similarly, the minimum bus p.u voltage was improved to $0.9722 \mathrm{p} . \mathrm{u}$ from $0.942 \mathrm{p} . \mathrm{u}$ (3.206\% improvement). 


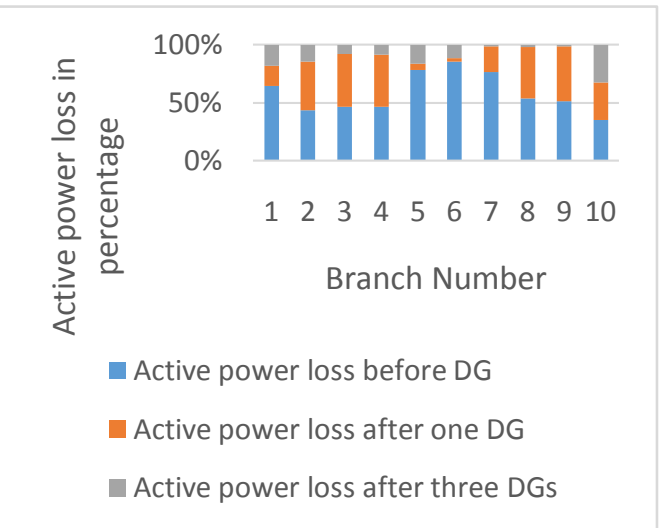

Fig. 10 : Active power loss profile of Sallaghari

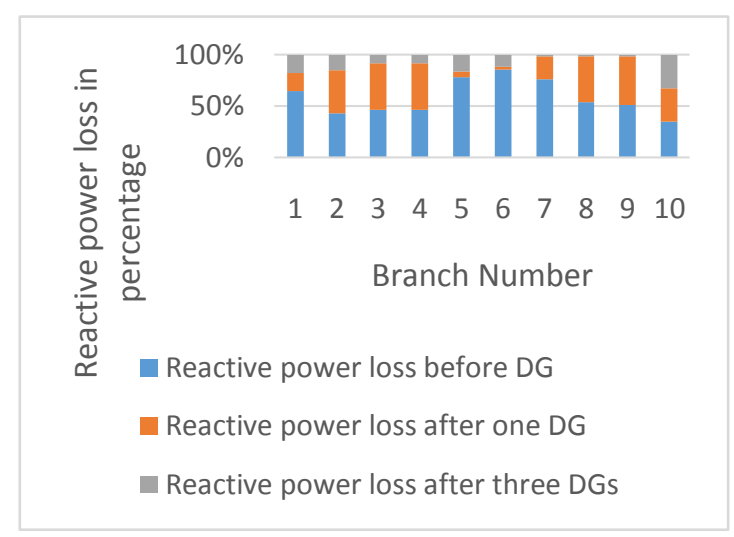

Fig. 11: Reactive power loss profile of Sallaghari

\subsection{Financial Analysis}

For financial analysis of DG integration in Sallaghari Feeder, the cost of electricity was taken as Rs. 11 per unit. The market interest rate was taken $10 \%$ and 1 U.S Dollar was taken equivalent to 100 Nepali Rupees. The life of capacitor and solar panel was taken 12 and 20 years respectively. The load factor was taken 0.6 and cost of capacitor and solar panel was taken $\$ 10$ per kVAR and $\$ 280$ per kW respectively.

Table 2: Financial Analysis of DG penetration in Thimi-Sallaghari feeder

\begin{tabular}{|r|r|r|r|r|r|r|}
\hline \multirow{2}{*}{ S.N. } & $\begin{array}{l}\text { No. } \\
\text { of } \\
\text { DG }\end{array}$ & $\begin{array}{c}\text { Equivalent Worth } \\
\text { Annual saving } \\
\text { (Rs.) }\end{array}$ & $\begin{array}{l}\text { Net Present } \\
\text { Value(NPV) } \\
\text { (Rs.) }\end{array}$ & $\begin{array}{l}\text { Simple } \\
\text { Payback } \\
\text { Period } \\
\text { (Years) }\end{array}$ & B/C ratio & IRR(\%) \\
\hline 1 & 1 & 1259974.239 & 720180.2872 & 8.152 & 1.04 & 11 \\
\hline 2 & 2 & 1402644.275 & 1942497.572 & 7.677 & 1.10 & 11 \\
\hline $\mathbf{3}$ & $\mathbf{3}$ & $\mathbf{1 4 1 2 3 4 5 . 7 9 5}$ & $\mathbf{2 0 7 8 1 2 0 . 2 0 4}$ & $\mathbf{7 . 6 2 5}$ & $\mathbf{1 . 1 1}$ & $\mathbf{1 2}$ \\
\hline 4 & 4 & 1397770.503 & 1922491.612 & 7.686 & 1.10 & 11 \\
\hline 5 & 5 & 1395101.288 & 1883010.302 & 7.701 & 1.10 & 11 \\
\hline 6 & 6 & 1362853.77 & 1649743.948 & 7.787 & 1.09 & 11 \\
\hline 7 & 7 & 1399009.288 & 1931850.722 & 7.682 & 1.10 & 11 \\
\hline 8 & 8 & 1367417.551 & 1687568.279 & 7.773 & 1.09 & 11 \\
\hline 9 & 9 & 1360204.563 & 1626657.387 & 7.797 & 1.09 & 11 \\
\hline 10 & 10 & 1388374.949 & 1845234.42 & 7.714 & 1.10 & 11 \\
\hline
\end{tabular}

The financial analysis was done for one to ten DG placements and from the results of Equivalent worth analysis, simple payback period, B/C ratio and IRR analysis, the best optimization was found to be three DG unit placement in Sallaghari Feeder. 


\section{Conclusion}

In this paper, Genetic algorithm for optimal DG allocation has efficiently minimized the total active and reactive power loss satisfying the voltage limit constraints in IEEE 33 bus test system and 11 bus Sallaghari Feeder distribution system. The study was carried out in MATLAB using "Backward and Forward Sweep Method" for load flow analysis and Genetic Algorithm for optimization. The number of DG units of different size integrated was varied from one to ten. The result of this study showed that the voltage at minimum voltage node, maximum active and reactive loss reduction of Thimi-Sallaghari feeder were improved by $3.69 \%$ (from 0.942 p.u. to 0.976 p.u), $75.88 \%$ and $75.88 \%$ respectively with placement of DG units at three bus locations of total $658.2019 \mathrm{~kW}$ and $395.873 \mathrm{kVAR}$ capacity. Likewise, the voltage at minimum voltage node, maximum active and reactive loss of IEEE 33 bus system were improved by $6.88 \%$, $90.11 \%$ and $89.9 \%$ respectively with placement of DG units of total $2215.488 \mathrm{~kW}$ and 1176.059 $\mathrm{kVAR}$ at 6 different locations of the network.

In addition to this, the financial analysis was performed to find the best optimal solution among ten DG unit placements in Sallaghari Feeder and from the analysis, it was found that the net annual saving, B/C ratio and IRR was found to be Rs.1412345.795, 1.11 and 12\% respectively for three DG unit placement which were highest among ten cases. So, from the results, the best optimization was found to be three DG unit placement in Sallaghari Feeder.

\section{References}

[1] Al-Abri R (2012), Voltage Stability Analysis with High Distributed Generation Penetration.

[2] Arif W and Naeem A (2016), Analysis and Optimization of IEEE 33 Bus Radial Using Optimization Algorithm, Journal of Emerging Trends in Applied Engineering, 1(2): 19-21.

[3] Chiradeja P and Ramakumar R (2004), An Approach to Quantify the Technical Benefits of Distributed Generation, IEEE Trans. Energy Convers, 19(4): 764-773.

[4] Gonzalez MG, López A and Jurado F (2012), Optimization of Distributed Generation Systems Using a New Discrete PSO and OPF. Electr. Power Syst. Res., 84(1): 174-180.

[5] Keane A (2007), Integration of Distributed Generation. University College Dublin.

[6] Masters CL (2002), Voltage Rise: The Big Issue When Connecting Embedded Generation to Long 11 kV Overhead Lines, POWER Eng. J., 16(1): 5-12.

[7] Regmi TR (2017), Optimal Allocation of Capacitor Bank for Loss Minimization and Voltage Improvement Using Analytical Method, Department of Electrical and Electronics Engineering, Kathmandu University, Nepal. 